This is a post-peer-review, pre-copyedit version of an article published in Higher Education, 2018, 76 (5), 753-770.

The final authenticated version is available online at:

https://doi.org/10.1007/s10734-018-0236-3

\title{
Institutional logics of Chinese doctoral education system
}

\author{
Authors: \\ Gaoming Zheng \\ Title: Ph.D. Candidate and University Instructor \\ Affiliation institution: Faculty of Management, University of Tampere \\ ORCID: 0000-0003-3182-6166 \\ Email: gaoming.zheng@uta.fi \\ Dr. Wenqin Shen \\ Title: Associate Professor \\ Affiliation institution: Graduate School of Education, Peking University, China \\ Email: shenwenqin@pku.edu.cn
}

Dr. Yuzhuo Cai

Title: Senior lecturer and Adjunct professor,

Affiliation institution: Faculty of Management, University of Tampere

ORCID: 0000-0002-7934-3828

Email: yuzhuo.cai@uta.fi

Corresponding author:

Gaoming Zheng

Email: gaoming.zheng@uta.fi

Telephone: +358505099277

To cite:

Zheng, G., Shen, W., \& Cai, Y. (2018). Institutional logics of Chinese doctoral education system. [journal article]. Higher Education, doi:10.1007/s10734-018-0236-3. 


\begin{abstract}
As Chinese doctoral education has grown dramatically in the past four decades and developed into one of the largest doctoral education systems in the world, it has become one significant and integral part of the global doctoral education landscape. However, in the literature there is a lack of both a comprehensive understanding of the Chinese doctoral education system and of generic frameworks for understanding doctoral education in a global context, with an emphasis on the underlying value systems. This may not only hamper the research on doctoral education in China but also affect international comparison and collaboration with Chinese doctoral education. Using the theory of institutional logics, this study tries to bridge the gap by identifying the complex value systems underlying the context of the Chinese doctoral education system, through a qualitative study mainly based on interview data and complemented by documentary data. The interview involves 135 participants, including 45 university academic leaders, 33 doctoral supervisors and 56 doctoral students from 17 research universities, as well as one government policy-maker. We found that the context of Chinese doctoral education system consists of multiple logics of state, profession, family, market and corporation. The special constellation of institutional logics has shaped the current Chinese doctoral education system as a state-led model but meanwhile incorporating family characteristics, market orientation and regulated academic autonomy. The study also showed that Chinese doctoral education has been developing in line with international academic norms and global marketization trends, and has also been shaped by China's socio-cultural tradition and the strong state regulation. In addition to the institutional logics analysis of the Chinese doctoral education system, this study paves the way for developing a novel framework for analysing doctoral education systems in other contexts and for comparative purposes.
\end{abstract}

\title{
Keywords
}

Doctoral education, Higher education, China, Context, Institutional logics 


\section{Introduction}

In recent years, China's rising position in the global doctoral education landscape makes the Chinese experience particularly salient (Yang 2012). The system has experienced dramatic development since its establishment in the 1980s, in response to both societal demands (Ma 2007) and governmental mandates (Zhao and Shen 2013; Yang 2012), and now it has become one of the largest doctoral education systems in the world, with 342,000 doctoral students enrolled in 2016 (MoE 2017). Meanwhile, some challenges are also recognised in the fast development process, such as the decline of quality in doctoral training (Yang 2012), conflicts between the differing needs of academia and the market ( $\mathrm{Gu}$ and Luo 2016), and lack of resilience due to centralised control by the state (Ma 2007). These challenges are not unique in China, but also exist in other systems in the world. Recently, there have been emerging interests and needs around the world, particularly Europe, to enhance the understanding of the Chinese system (Bao et al. 2016; Zhu et al. 2017), which also calls for research attention to the contextual factors affecting the Chinese doctoral education.

In the previous studies, there has been an increasing awareness of the importance of the context in comparative education research and international development (Crossley 2009; Crossley and Jarvis 2001; Crossley 2010), the analysis of higher education systems and universities (Välimaa 2008), and the studies of Chinese education (Hayhoe 1996;Gu 2004; Cai 2010, 2012; Yang 2011, 2017; Hawkins 2013). A recent study on doctoral supervision for Pacific Islanders in New Zealand particularly suggested that cultural context matters and empowers supervision practices (Carter et al. 2017). However, the research on the cultural context of the Chinese doctoral education system is lacking in both the Chinese and the English literature.

In the Chinese literature, Chinese doctoral education has been well documented, and many studies have to varying extents contributed to our current understanding of the system. However, their focus has mostly remained on the description or analysis of one or more specific issue(s), e.g. the system's expansion (Zhao and Shen 2013; Guo 2009), supervision mode (Shen and Fan 2013; Shen et al. 2017), financial aid for doctoral students (Peng 2009) and graduate employment (Liu and Luo 2015; Gao and Shen 2016). Quality issues have by far attracted the greatest attention in the literature. Evaluation of quality (Shen 2009; Chen et al. 2011; Fan et al. 2011), mechanisms to enhance quality (Chen et al. 2016; M. Wang et al. 2016) and factors influencing quality (Chen 2010) are all heated topics under discussion. Furthermore, few of these have employed any specific theoretical framework to enhance the analysis of the issues addressed, especially in dealing with contextual issues. Nevertheless, some studies have attempted to narrow the gap in this regard. For instance, Guo (2009) understood the expansion of the Chinese system from the perspective of institutional theory and explained the impact of international normative influence and the national regulative force on the expansion process. $\mathrm{Wu}$ (2013) analysed the institutional pressure that may result in the current challenges for Chinese doctoral students. Unfortunately, neither of them has identified what exactly the contextual elements are in the institutional environment.

The literature published in English has not provided useful tools to analyse the contexts of Chinese doctoral education, either. The most relevant literature in one way or another touching upon the topic can be categorised into three groups, namely system overviews, quality issues and international perspectives. Ma (2007) and Yang (2012) presented an analytical overview of the Chinese doctoral education system from the perspective of historical development with different highlights. On the quality issue, Gu et al (2011) concentrated on the quality of doctorates and indicated that the academic origin of doctoral graduates and supervisors' academic status had a significant impact on the research performance in doctorates. Siu (2011) examined the quality of joint supervision and identified it as a double-edged sword. A recent study by Gu et al (forthcoming) explored the relation between students' career choices and the quality of supervision from the perspective of career development theory. From an international (comparative) perspective, some researchers explored the experiences and performance of Chinese doctoral students or Chinese-foreign doctoral programmes in an international context from different theoretical approaches. These included epistemological development theory (Zhu 2017), world system theory (Kim and Roh 2016), the institutional logics approach (Zheng et al. 2017) and the socialisation model (Wu 2017). Others paid more attention to the comparison between China and other systems on a certain issue, such as the trend of reform and development (Bao et al. 2016), professional doctorates (Wildy et al. 2015) and the doctoral experiences from the theoretical lens of organisational socialisation (Rhoads et al. 2016).

Hence in both the Chinese and the English literature, there is a research gap concerning exploring the contextual factors of Chinese doctoral education system particularly in terms of a well-developed analytical framework and rich empirical evidence. The great challenge to fill the gap lies in how to conceptualise the abstract term of context in a more concrete way. As commented in previous study (Cai 2015) regarding studies dealing with contextual issues, 'while scholars are aware of the importance of context effect, few have attempted to make explicit what the context is'. Indeed, this is also a research challenge in higher education research in general. Many educationalists refer by 'context' to social, cultural, economic and political 
contexts (Yang 2011) or understand elements of context to include political, linguistic, cultural, economic and geographical factors (Bray and Gui 2001). In this respect, they largely concur with the insights of institutional theory, which treats the context as the institutional environment, referring to rules, norms, understandings, beliefs and taken-for-granted assumptions about what constitutes appropriate or acceptable organisational forms and behaviours (Meyer and Scott 1983). Even in the field of institutional analysis, one challenge is to render the institutional environment concrete.

One solution to this challenge is the institutional logics approach (Cai 2015; Cai and Mehari 2015), which is able to concretize the very abstract concept of the institutional environment by identifying a set of organising principles that imbue actions and conflicts with meaning (Thornton and Ocasio 1999). Institutional environment is constituted by institutional logics/orders, which are 'the socially constructed, historical pattern of material practices, assumptions, values, beliefs, and rules by which individuals produce and reproduce their material subsistence, organize time and space, and provide meaning to their social reality' (Thornton and Ocasio 1999, 804). Furthermore, given a widely accepted claim on the complexities and ambiguities of the higher education system (Clark 1983; Pinheiro 2011), there has also been an emerging awareness that the institutional logics approach is influentially useful in higher education studies (Lepori 2016; Cai and Mehari 2015; Bleiklie et al. 2017). Previous studies either on various themes of higher education (Cai 2014; Cai and Zheng 2016) or more specifically on the topic of doctoral education (Mars et al. 2014; Gu and Luo 2016; Zheng et al. 2017) all have proved the explanation power of institutional logics to grasp the context of a doctoral education system.

Therefore, by using the institutional logics approach, this paper tries to fill the aforementioned knowledge gap through answering the research question: What are the institutional logics underlying the context of the Chinese doctoral education system? To answer this question, we will first construct an analytical framework from an institutional logics perspective and then use the framework to guide our qualitative analysis of both primary data of interviews and secondary data of academic literature and policy documents.

\section{Institutional logics as an analytical framework}

When applying an institutional logics approach to higher education studies, ideal types of institutional logics (Thornton et al. 2012) have become a frequently used tool to understand the institutional complexity (Bleiklie et al. 2017). Thornton et al (2012) identified seven ideal types of societal-level logics, and suggested that logics at the organisational and field levels are subject to the societal-level logics. We define the seven ideal types of logics based on a review of the literature:

State logic: State is a redistribution mechanism (Thornton et al. 2012). Therefore, the focus of state logic is to convert diverse issues into the basis for routine official decisions that can be made either by consensus or majority vote (Thornton et al. 2012; Friedland and Alford 1991). As such, state logic entails rationalisation and the regulation of human activities by legal apparatus and bureaucratic hierarchies (Friedland and Alford 1991).

Profession logic: Following profession logic, a person's reputation is connected to the quality of their craft, and actors all seek to improve their personal expertise and thus enhance their status in the professional community (Thornton et al. 2012).

Family logic: 'Families attempt to convert all social relations into reciprocal and unconditional obligations oriented to the reproduction of family members' (Friedland and Alford 1991, 249). In family logic, patriarchal power dominates in society, and actors as family members seek to increase their families' honour (Thornton et al. 2012).

Market logic: Market logic attempts to convert all human activities into the transaction of commodities that have a monetary price (Thornton et al. 2012; Friedland and Alford 1991). It emphasises a strategy of increasing profits and efficiency (Thornton et al. 2012).

Corporation logic: The actors in a society/organisation of corporation logic become employees under the control of corporate managers (Blau and Scott 2003). Corporation logic emphasises efficiency in managerial practices (Thornton et al. 2012).

Religion logic: The logic of religion 'attempts to convert all issues into expressions of absolute moral principles accepted voluntarily on faith and grounded in a particular cosmogony' (Friedland and Alford 1991, 249). Actors seek to increase the religious symbolism of natural events (Thornton et al. 2012).

Community logic: Community is constituted by a common group boundary and by social action that is driven by the satisfaction of common economic needs, and value systems that influence its economy (Thornton et al. 2012). Members of a community try to cover each other's losses and increase the honour and status of group members (Thornton et al. 2012). 
When examining the doctoral education system in China, we mainly focus on the following dimensions: admission, doctoral training, quality assurance, graduation, governance and funding, which have been commonly discussed in the literature on the Chinese doctoral education system (CQAGDE 2010; Yang 2012).

Therefore, by combining the ideal types of institutional logics (X-Axis) with the dimensions of a doctoral education system (Y-Axis), we develop an analytical framework for the study (see Table 1). By cross-examining the Y-Axis and the XAxis, we can identify the institution logics in the context of a doctoral education system and analyse their reflections/impacts on each dimension. Nevertheless, although we list all the seven ideal types in the framework, some of the logics may be less relevant or noticeable in the context.

Table 1 Analytical framework

\begin{tabular}{|c|c|c|c|c|c|c|c|c|}
\hline & X-Axis: Ide & pes of & stitutional l & & & & & \\
\hline \multirow{7}{*}{$\begin{array}{l}\text { Y-Axis: } \\
\text { dimensions of } \\
\text { a doctoral } \\
\text { education } \\
\text { system }\end{array}$} & & $\begin{array}{l}\text { State } \\
\text { logic }\end{array}$ & $\begin{array}{l}\text { Profession } \\
\text { logic }\end{array}$ & $\begin{array}{l}\text { Family } \\
\text { logic }\end{array}$ & $\begin{array}{l}\text { Market } \\
\text { logic }\end{array}$ & $\begin{array}{l}\text { Corporation } \\
\text { logic }\end{array}$ & \begin{tabular}{|l|} 
Religion \\
logic
\end{tabular} & \begin{tabular}{|l} 
Community \\
logic
\end{tabular} \\
\hline & Admission & & & & & & & \\
\hline & $\begin{array}{l}\text { Doctoral } \\
\text { training }\end{array}$ & & & & & & & \\
\hline & $\begin{array}{l}\text { Quality } \\
\text { assurance }\end{array}$ & & & & & & & \\
\hline & Graduation & & & & & & & \\
\hline & Funding & & & & & & & \\
\hline & Governance & & & & & & & \\
\hline
\end{tabular}

\section{Research methods}

This study employs a qualitative research method mainly based on primary data and complemented by secondary data. The primary data as our main data sources are from our interviews about different stakeholders' perceptions of Chinese doctoral education. We conducted 70 interviews involving 135 participants from 17 research universities and the China Academic Degrees and Graduate Education Development Center under the Minister of Education and State Council jointly (CADGEDC), from 2004 to 2015. Among them, 53 were individual interviews, involving one university vice rector, 13 deans of university graduate schools, 14 deans of faculties, 24 supervisors, and 1 officer in CADGEDC. Seventeen were focus-group interviews covering 82 participants, with a size ranging from 3 to 17, involving all together 56 students, 9 supervisors and 17 university administrators. All the interviews were in Chinese, recorded and transcribed. The secondary data cover academic literature related to Chinese doctoral education, including 92 Chinese academic papers and 12 English academic papers, and the state government's policy documents concerning doctoral education and doctoral degrees in China available by 2017 on the official website of the CADGEDC (CADGEDC 2017).

When it comes to data analysis, first, on the basis of the analytical framework constructed, we developed 13 categories for coding, including the six dimensions of doctoral education (see Y-Axis of Table 1) and the seven ideal types of institutional logics (see X-Axis of Table 1). Second, we examined and coded the collected data (both primary and secondary data) in the coding categories developed, by considering which dimension the text was concerned with, whether they reflected the ideal types of logics, and which logics they were representing. Some texts were coded into more than one category where appropriate. 
Third, after finishing the coding, we generated the coding matrix by cross-examining the codes on each dimension of doctoral education and those on each category of ideal types of logics, selected out the codes that were present on both a dimension and in a logic, and placed them in the coding cell of the matrix. Then we analysed and summarised the content of coded texts in each cell of the coding matrix and came up with our findings.

\section{Analysis}

Based on the analysis of data, we identify five underlying logics in the context of Chinese doctoral education, including state logic, profession logic, family logic, market logic and corporation logic. Religion logic and community logic were hardly perceptible and the reasons for this remain uncertain. However, we assume it may be associated with a relatively weak religion logic in Chinese society as well as the fact that most universities offering doctoral education in China are under the direct administration of governmental ministries or provincial governments and thus seldom involved with local communities. Next we explain each of the five logics, which are evidenced by the data, along the six dimensions of doctoral education system.

\section{State logic}

The evidence supporting the state logic in Chinese doctoral education are primarily from the secondary data. State logic has long been embedded in Chinese educational system since Keju, i.e. the Chinese national civil servants' selection examination, was adopted in the year 607 or even earlier. The main purpose of education was to cultivate qualified civil servants for the government $(\mathrm{Gu}$ 2004). Hence we were not surprised to discover the state logic when analysing the data. In fact, the developmental path of Chinese doctoral education indicates strong promotion and tight control by the central government (Yang 2012). The system was supposed to represent the will of the state and 'contribute to the enhancement of our nation's international competitiveness and the improvement of the nation's economy', as the policy-maker from CADGDC stated. The state logic is reflected in all the six dimensions of doctoral education.

\section{Admission}

Influenced by the state logic, the Ministry of Education (MoE) regulates admission to doctoral education by setting the general recruitment criteria and planning the number of students admitted. Although today universities have more autonomy in designing the means of admission, all doctoral applicants still need to participate in a national graduate entrance examination and pass in some subjects required by the state. The government is involved in deciding the annual intake, including the ratio of internal and external candidates in order to curb nepotism (MoE 2014). The expansion of the system since the 1990s has been driven and regulated by the national government (Zhao and Shen 2013). The process of planning and distributing the enrollment quota is a reflection of state logic in regulating and distributing public resources.

\section{Doctoral training}

Analysis of the literature and interviews both showed that the government plays a weaker role as regulator in training activities, mainly in outlining the goals and the scope of doctoral education. Within the state-set framework, universities further design their own curricula.

\section{Quality assurance}

Both the documentary and interview data suggested that the state is currently the gatekeeper and external quality assurer of the system in China. First, the government has the authority to decide which universities are eligible to provide doctoral education and which doctoral programmes can be opened for student recruitment (Guo 2009). Through this, as well as planning the annual intake, the government controls the scale of the doctoral education system in China (Yang 2012). Second, the approved doctoral programmes and the doctoral dissertations completed are under the state's external assessment. Four doctoral programmes were cancelled in 2014 after the assessment (MoE 2016). If dissertations are deemed inadequate for graduation, the candidates' doctoral degrees will be recalled and their supervisors will face a temporary suspension of their supervision rights (CADGEDC 2016c). Third, interviews with supervisors and students showed that a strict quality evaluation system of the process of completing doctoral dissertation has been established, which is also a reflection of state logic (Zheng 
et al. 2017). A doctoral candidate in China is required to pass the research proposal presentation, mid-term assessment, doubleblind peer review, pre-defence evaluation and finally the official defence in order to get his/her dissertation submitted.

\section{Graduation}

A doctoral degree in China is a 'state qualification' (Chen et al. 2016), which was also mentioned repeatedly in the interviews by different stakeholders. It must meet the standards stipulated by the state and can only be conferred by those institutions which are authorised by the government (CADGEDC 2016b). Besides, in relation to the dimension of doctoral training, the government also outlines the basic graduation criteria.

\section{Funding}

The literature shows that when the doctoral education system was established, it was fully financed by the government (Peng 2009). Nowadays, although government support is not the sole financial source, the central government remains the major financial supporter and the resource distributor. The government allocates funding to doctoral students according to their merits and needs, and to universities by considering the annual student intake and the research capacity (university ranking, research labs and facilities, etc.) of universities and supervisors (MoE 2005, 2014).

\section{Governance}

As noted, the state wields strong power in the system-level governance. It acts as the gatekeeper of the system, controls external quality assurance and is the major funder. Moreover, through multiple polices and regulations, such as Project 985 and Project 211, the development of graduate schools in some selected universities, the Key Disciplines Policy and the most recent 'Double First-class University' policy, the Chinese government has developed a hierarchy within the Chinese higher education system (Cai and Yan 2015). Top universities receive more financial support from the government and enjoy greater autonomy (Wang 2008). Parallel to this, a hierarchical national-provincial-institutional academic degree management system had been established to regulate the conferring of academic degrees in China (CADGEDC 2016a).

Moreover, the interviews with stakeholders in universities suggested that the state logic is also reflected in the strong bureaucratic power inside universities. One prime example is the decision-making power of the graduate school in deciding how the state-approved intake shall be distributed among the faculties. Some interviewees suggested that even though autonomy has been devolving from government to universities, the power mainly falls into the hands of the administrators rather than the hands of academics. Meanwhile, because of the heavy bureaucracy, many supervisors need to fulfil some administrative tasks. During the interview, a student complained to us and said 'I feel that I need to compete with the administrative power for my supervisor's time'.

\section{Profession logic}

As doctoral students are the next generation of academics (Austin 2002), and most of them complete their anticipatory socialisation to the academic profession during their doctoral studies by learning about academics in their disciplines and in the profession (Tierney and Rhoads 1993), naturally profession logic is embedded in the field of doctoral education. The Chinese doctoral education system is no exception. Both primary and secondary data demonstrated a strong profession logic in China's doctoral education in all the six dimensions:

\section{Admission}

Driven by profession logic, students' research expertise is the major recruitment criterion, and this was largely supported by the interviews with supervisors. Many of the supervisors interviewed maintained that recruiting excellent students is vital to ensuring the quality of doctoral education. By 'excellent students', they refer to students with capacity for critical thinking and research. Regarding the question of how to recruit excellent students, supervisors argued that more autonomy should be devolved from the government. For instance, 'cultivating research talents through the master-doctoral consecutive programmes is beneficial, but it is uncourageous in the current recruitment policy as it would occupy the quota of intake twice. Once in master's admission, and another time in doctoral admission', as stated by a supervisor from Peking University. Many other supervisors shared his opinion, and they hoped the university could have more power in deciding the structure of the annual intake. For another example, one supervisor from Fudan University mentioned there should be more flexibility in 
choosing candidates for interview, which many supervisors believed was crucial to determine students' research capacity. As he maintained, 'Currently the rate of the recruited candidates versus potential candidates who can attend for interview in my faculty is strictly 1: 1.2. For me, it does not really matter whether the rate is 1: 1.2 or 1:2. Allowing more candidates attend the interview component can allow me to have more choices for selecting the excellent students'.

\section{Doctoral training}

In consonance with the international norms, the enhancement of doctoral students' research capacity and the production of new knowledge is the core goal of doctoral training activities in China, which is indicated in the policy documents and also taken for granted by the interviewees. For instance, in our interviews, Chinese doctoral supervisors showed their encouragement for students to get involved in the international academic community through all kinds of academic activities, and students also expressed their strong interest to do so.

\section{Quality assurance}

The majority of the doctoral supervisors interviewed saw quality as 'Excellence 1', which implies recruiting the right students and providing the right environment to give opportunities for students' development (Harvey and Green 1993). Analysis of interviews showed that Chinese supervisors and students shared the common values of academia that 'quality (of academic work) is assured by peer review and academic freedom' (Enders and Musselin 2008, p. 145), and doctoral dissertations are all submitted for peer review.

\section{Graduation}

Related to the evaluation standard of quality, the analysis of policy documents indicated that the graduation criteria in China are set to ensure that Chinese doctors can be recognised as qualified academics. In line with this thinking, the supervisors interviewed also expected doctors to continue in their academic careers. When nowadays more and more doctoral graduates enter industry, some supervisors expressed their regret in our interviews.

\section{Funding}

Also in association with the quality evaluation, both in policies and practices, research capacity is recognised by all interviewees as the major consideration factor for research resource distribution. For instance, the government allocates more funding to the universities at the top of the system hierarchy for doctoral research, and many interviewees believed this is because these universities have superior research capacity. Many interviewees also suggested that those supervisors who enjoy high reputations also get more research funding and are allowed to recruit more doctoral students. Some students and administrators interviewed suggested that students' scholarships were awarded to students mainly based on their academic performance, and it was fair.

\section{Governance}

Doctoral supervisors who are superior in research expertise play a decisive role in the supervision process (CQAGDE 2010). This is common in traditional apprenticeship and widely accepted by most of the supervisors interviewed. However, in the Chinese context, this is also related to family logic, which will be explained next.

\section{Family logic}

Family logic has not been discussed much in the literature, and in our study, we mainly see it from the interview data. Yet if we trace its origin in the literature, we find that it comes from the taken-for-granted family values in Chinese traditional education. Traditionally in China, teachers were regarded as important as parents (Gu 2004). The relationship between teachers and students was considered a parent-child relation ( $\mathrm{Gu}$ et al. forthcoming). Under the impact of such strong family values, a shimen culture was nourished in the Chinese doctoral education system. Literally, shi (Chinese) is teachers and men (Chinese) is family. A doctoral shimen is a research family, consisting of a doctoral supervisor and all his/her supervisees. In China, doctoral education is carried out within a shimen, inside which, in addition to the supervisor, the elder academic siblings also 
provide guidance for the younger academic siblings. Shimen culture bears strong family characteristics and can be observed in all the six dimensions of Chinese doctoral education.

\section{Admission}

Under its impact, almost all supervisor interviewees preferred to recruit doctoral students from among their master's and bachelor's supervisees. One supervisor interviewed argued that this is because the supervisors know those students from their shimen better, and they can select the most suitable students. Hence, they argued for bigger quotas to recruit students from their shimens.

\section{Doctoral training}

Interviews with students and supervisors showed that the doctoral supervision in China extends from academic issues to all kinds of non-academic issues in students' lives. For instance, one professor from Peking University said, 'Sometimes when they have relationship problems, I even need to comfort them. This really makes me like their parent outside their home'. Interviews with supervisors and students showed that this to some extent enhanced the trust between supervisors and students and thus enhanced the quality of supervision. However, some supervisors also felt pressed by this 'family responsibility'.

\section{Quality assurance}

Theoretically, the concept of quality of doctoral education does not entail family logic (Zheng et al. 2017). When we noticed its influence in the Chinese context, we also found its impact was rather negative. Supervisors in the interviews suggested that they felt pressured about failing their substandard students, particularly when these substandard students pushed their supervisors to think about them as their children and to approve their dissertations without sticking strictly to the academic standard. This 'family pressure' was one of the reasons behind the high completion rate in the Chinese system.

\section{Graduation}

Except for what was mentioned about the high completion rate, a recent study showed that many Chinese supervisors recommend their students for work opportunities where they have connections (Gu et al. forthcoming), which, as our interviews indicated, was also expected by students. A student from Nankai University claimed, 'supervisors should also help students develop their career path...I hope supervisors can think of our future as our parents do'.

\section{Funding}

The interview data also indicated that the reputation of the shimen has influenced the research resource allocation. For instance, some interviewees maintained that in the previous competition for the National Excellent Doctoral Dissertation Award, not only the contribution of the students' doctoral research, but also their supervisor's and shimen's reputations were considered, even though the latter factor was not stipulated in the evaluation documents.

\section{Governance}

Supervisors' and students' perceptions of the supervisor-student relation in the interviews showed that, together with profession logic, family logic affirms the dominant role of supervisors in the shimen's governance. Almost all supervisors and students thought a doctoral supervisor in China is a patriarchal leader of a shimen, and the relationship between a supervisor and his/her supervisee is one of patronage, in which the supervisor takes care of his/her students within a hierarchical governance mode. 'Relations between us (students) and supervisors...are a hierarchical relation. It is not equal at all', according to a student interviewee and supported by many other interviewees. Some student interviewees were worried about their supervisors' overwhelming power. 'Supervisors have the ultimate power to decide whether we can graduate. There could be more approaches to ensure the justness of their decisions.', as a student from Nanjing University stated. 


\section{Market logic}

Both the documentary and interview data suggested that the impact of market can be seen in the aspects of doctoral training, graduation and funding. Market logic was introduced into the Chinese educational system in the 1980s, when the market forces were allowed to enter into the system (Cai 2010).

\section{Doctoral training}

The literature shows that project-based doctoral supervision is becoming popular in China. For instance, by 2010, $85.6 \%$ of the doctoral students in China had participated in research projects during their doctoral studies, of which $88 \%$ were related to their doctoral research (CQAGDE 2010). However, the supervisors interviewed also expressed their concern about project-based supervision. For instance, '(In research projects), doctoral students are just doing what is required by their supervisor without their own thinking...actually it (project-based supervision) is not beneficial for students', according to a supervisor.

\section{Graduation}

Many student interviewees suggested that they have to begin their jobseeking very early. And a recent study also showed that Chinese graduates were increasingly choosing non-academic professions (Gu et al. forthcoming). The students interviewed explained that the reasons were threefold: First, an academic career is very competitive nowadays. Second, projectbased supervision increased the opportunities to collaborate with non-academic organisations and attracted more graduates to work outside the academic field. Third, the salaries in industry are usually higher than in universities.

Besides, some interviewees mentioned that to some extent a doctoral degree becomes a profitable asset for social and economic status enhancement. 'Actually what they want is not the enhancement of research capacity, but the title of a doctor!' as one supervisor criticiced. Nevertheless, such a phenomenon does not solely result from market forces, but is also connected to the Chinese tradition; because of which, a higher academic degree means a higher position in the government and higher social status (Gu 2004).

\section{Funding}

Similarly, some interviewees also indicated that the right to offer doctoral education became a profitable asset for universities. A prominent professor from Shanghai Jiao Tong University explained the phenomenon, 'Many universities asked me to recommend them (for the right to offer doctoral education)... actually, it is all because the government connects funding allocations to doctoral education provision. Universities that have that right can apply for more funding, research projects...eventually every university wants to become a research university ...but we don't need all universities to be research universities!'. Besides, aligned with the global trend, the literature shows that the funding sources for doctoral education in China have been under diversification (CQAGDE 2010).

\section{Corporation logic}

The corporation logic was introduced into China's system together with the market logic since the marketization of Chinese higher education in the 1980s (Cai 2010). The impact of cooperation logic is mainly seen in the analysis of the interview data. It is rather weak in the Chinese system, which can be observed in the dimensions of doctoral training, funding and graduation.

\section{Doctoral training}

From the interviews it seems it was common in some disciplines that supervisors 'hired' students to complete research projects for them and a quasi-corporate employment relationship between supervisors and students develops. Many students called their supervisor 'boss' in our interviews.

\section{Graduation}

Driven by the corporation logic, academic publication, a visible indicator of efficiency and effectiveness of resource investment becomes a graduation criterion. However, this criterion was heavily discussed in many interviews and was not accepted by many supervisors and students. Most of the supervisors interviewed believed the quality of research work, instead of the quantity of publications should be considered as a graduation criterion. A professor from a research institute in Shanghai explained, 'Completion of a piece of academic work does not tell a student's research capacity. Those published papers are 
usually quite small-scale studies (compared to doctoral dissertations). A student's research capacity is shown in the process when he/she complete his/her doctoral research independently'.

\section{Funding}

Even though it was not widely adopted, it seems in some interviewees' universities they awarded students based on the quantity of academic publication. This was a reflection of cooperation logic on performance-based management.

\section{Discussion}

After our analysis of the underlying logics in the Chinese doctoral education system, we try to come up with more generic descriptions of these logics as follows, which may have potential to be applied to understand the field of doctoral education.

State logic: with respect to state logic in the field of doctoral education, actors with bureaucratic power, such as state governments and university administrators, exert the greatest influence. They intend to construct a hierarchical doctoral education system through government policies and regulations, routine administration and the redistribution of resources. Doctoral education is deemed a public good and should represent the interests of the state government.

Profession logic: driven by profession logic, a person's status in doctoral education rests on his/her personal expertise in disciplinary research. Doctoral supervisors who have more advanced expertise in the discipline enjoy a higher reputation in the academic community and have more authority in doctoral education. Actors in the field including both doctoral supervisors and doctoral students seek to enhance their personal expertise, gain recognition among their peers and enhance their status in the academic community.

Family logic: in the context of doctoral education driven by family logic, a research group consisting of a supervisor and his/her supervisees becomes a family unit, called a supervision family, in which the doctoral supervisor acts as the patriarchal leader, and the supervisees become children. The relationship between a doctoral supervisor and his/her supervisees is a patronage relationship based on reciprocity. Doctoral students and doctoral supervisors behave like family members, express their unconditional loyalty towards their supervision family and seek to enhance the family honour together.

Market logic: according to market logic, doctoral education, doctoral degrees and doctoral graduates become profitable commodities and valuable assets in the market. The pursuit of a doctoral education is driven by the intention to increase the stakeholders' profits. Market and market-like activities are introduced, which increases competition in the context of doctoral education and favours applied doctoral research, especially industry-collaborative research.

Corporation logic: driven by corporation logic, the efficiency of doctoral education isemphasised, and performancebased management is implemented in the organisation of doctoral education. Hence, on-time graduation, academic publication and other activities that can demonstrate the effectiveness and efficiency of doctoral education management are encouraged. An employment relationship between universities and doctoral students is established as part of the process of managing doctoral education.

Furthermore, by tracing the origins of the identified logics in history as shown in the analysis, we found that the true inner forces behind the underlying logics are the state power, international academic norms, market influence and Chinese cultural tradition. The inner forces for the identified logics are almost aligned with the Clark's triangle of coordination in the higher education context (Clark, 1983), as state logic is imposed by the state authority, the profession logic by the academic oligarchy and the market logic and corporation logic by the market (Bleiklie et al. 2017). However, what is missing in earlier studies based on the realities of Northern America and Europe (Bleiklie et al. 2017; Clark 1983) is the discussion about the family logic from the Chinese cultural tradition. Our analysis results regarding family logic provide direct evidence of the strong influence from cultural tradition on the field of doctoral education in China and highlight the importance of considering Chinese higher education in the light of Western values together with the Chinese socio-cultural context (Yang 2017). Such finding also manifests a mismatch between western theoretical frameworks and China's higher education context as already indicated in some earlier research (Wang 2010). 


\section{Conclusion}

The study, from the institutional logic perspective, for the first time provides a comprehensive analysis of the context of the Chinese doctoral education system. In summary, the development of the Chinese doctoral education system has adopted the international academic experiences and put them to work in the Chinese socio-cultural context under strong regulation by the state and increasingly strong market forces. As a result, currently the institutional environment for doctoral education in China consists of the logics of state, profession, family, market and corporation. Influenced by such a constellation of logics, the current Chinese doctoral education system has developed its distinctive features:

(1) As addressed in many previous studies (Yang 2012; Guo 2009), the system is strongly regulated by the state and meanwhile highly dependent on the state's support.

(2) Norms and values of the international academic world are shared and even taken for granted by supervisors and students in China.

(3) Chinese doctoral supervision is characterised by strong family values, which has not been, but actually should have been thoroughly addressed in earlier research.

(4) The identities of doctoral students in China are complex. They are not only academic apprentices and junior research workforce, but also academic children.

(5) The relation between supervisors and students is not only professional ties, but also a parent-child relation. In most cases, it is hierarchical.

(6) At institutional level, a strict and systematic quality management process has been developed to ensure quality.

(7) While a low completion rate has been a concern for many universities in the West and been related to the performance of universities and students (Ghignoni 2017; Robinson 2004), this is not the case in China. On the contrary, the completion rate has been high in China, which has been one of the major concerns in ensuring quality.

The features of Chinese doctoral education mentioned above are interrelated, and all lead us to think about an issue causing widespread concern, that is, the quality of doctoral education. Based on the study of underlying logics, we propose that to enhance the quality of doctoral education in China, the professional identity of doctoral students in China should be further developed and their social and economic status should be enhanced. The process of doctoral training is a socialisation process of doctoral students to become academics, in which only by identifying the professional identity of doctoral students can they develop into competent scholars with the capacity for independent thinking. In order to do so, first, the impact of family logic should be restricted and profession logic should always be given a prominent place in doctoral training. For instance, doctoral supervision should mainly concern academic issues. Second, the power of the influence of state logic should be further decentralised regarding funding. To be an independent academic, a doctoral student should be financially independent as well. For instance, external funding resources, such as funding from research councils, various foundations and industries should be open for doctoral students to apply directly to support their doctoral research, through which can the funding pressure on the government be relieved, and the income for doctoral students be increased. Third, to reduce the impact of family logic on quality evaluation, international experts could be invited to participate in the peer review of doctoral students' dissertations. In so doing, Chinese doctorates can also gain increasing recognition by the international academic world. Last but not the least, considering the strong state logic in the Chinese system, to implement the aforementioned suggestions, it would be more effective if they could be implemented with support from government policy.

In addition to the added value for research and practices in Chinese doctoral education, the significance of our study also lies in contributing to the knowledge pool by identifying and defining the logics in the field of doctoral education and proposing a generic analytical framework to understand the field. While the framework has proved useful in the Chinese context, it is expected also to be applicable to doctoral education systems elsewhere and for purposes of comparative research. For instance, in a follow-up study, we together with our colleague (Zheng et al. forthcoming) applied the framework to compare the Finnish and Chinese systems. We first identified the underlying logics in both systems and investigated similarities. Even influenced by the same logics, we compared the similarities and differences of the reflections/influences of the underlying logics. Through this approach, we discussed the compatibilities and challenges in developing cooperation between the two systems. Such an approach can also be applied to other doctoral education systems, thereby providing a much more applicable and analytical perspective to compare different systems. 


\section{References}

Austin, A. E. (2002). Preparing the next generation of faculty: graduate school as socialization to the academic career. The Journal of Higher Education, 73(1), 94 -122.

Bao, Y., Kehm, B. M., \& Ma, Y. (2016). From product to process. The reform of doctoral education in Europe and China. Studies in Higher Education, 1-18, doi:10.1080/03075079.2016.1182481.

Blau, P. M., \& Scott, W. R. (2003). Formal organisations: A Comparative Approach (2nd ed., Vol. Book, Whole). San Francisco, CA: Standford University Press.

Bleiklie, I., Enders, J., \& Lepori, B. (2017). Organizational ConfigurationOrganisationalConfigurations of Modern Universities, Institutional Logics and Public Policies-Towards an Integrative Framework. In I. Bleiklie, J. Enders, \& B. Lepori (Eds.), Managing Universities: Policy and Organizational Change from a Western European Comparative Perspective (pp. 303-326). Cham: Springer International Publishing.

Bray, M., \& Gui, Q. (2001). Comparative Education in Greater China: Contexts, characteristics, contrasts and contributions. Comparative Education, 37(4), 451-473, doi:10.1080/03050060120091256.

CADGEDC (2016a). Chinese Academic Degrees Management Structure (In Chinese). http://www.cdgdc.edu.cn/xwyyjsjyxx/xwbl/gltz/gltz/260207.shtml. Accessed Web Page 2016.

CADGEDC (2016b). Evaluation and Authorization System of Institutions for Conferring Degrees (In Chinese). http://www.cdgdc.edu.cn/xwyyjsjyxx/xwbl/xwzd/xwsqshzd/. Accessed Web Page 2016.

CADGEDC (2016c). National random check of doctoral education dissertations (in Chinese). http://www.cdgdc.edu.cn/xwyyjsjyxx/zlpj/bslwccps/. Accessed Web Page 2016.

CADGEDC (2017). Policy documents and regulations on academic degree management and graduate education http://www.moe.gov.cn/s78/A22/A22_zcwj/. Accessed 12/18 2017.

Cai, Y. (2010). Global Isomorphism and Governance Reform in Chinese Higher Education. Tertiary Education and Management, 16(3), 229-241, doi:10.1080/13583883.2010.497391.

Cai, Y. (2012). Traditional reform philosophy and challenges of higher education reforms in China. International Journal of Humanities and Social Science, 2(6), 61-69.

Cai, Y. (2014). Implementing the Triple Helix model in a non-Western context: an institutional logics perspective. Triple Helix, l(1), 1-20, doi:10.1186/s40604-014-0001-2.

Cai, Y. (2015). What contextual factors shape "innovation in innovation"? - Integration of insights of the Triple Helix and the institutional logics perspective. Social Science Information, 54(3), 299-326, doi:10.1177/0539018415583527.

Cai, Y., \& Mehari, Y. (2015). The use of institutional theory in higher education research. In J. Huisman, \& M. Tight (Eds.), Theory and Method in Higher Education Research III (pp. 1-25). Bingley: Emerald.

Cai, Y., \& Yan, F. (2015). Demands and Responses in Chinese Higher Education. In S. Schwartzman, R. m. Pinheiro, \& P. Pillay (Eds.), Higher Education in the BRICS Countries: Investigating the Pact between Higher Education and Society (pp. 149-169). Dordrecht: Springer Netherlands.

Cai, Y., \& Zheng, G. (2016). University academic promotion system and academic identity: An institutional logics perspective. In L. Leisyte, \& U. Wilkesmann (Eds.), Organizing Academic Work: Teaching, Learning, and Identities (1st ed., pp. 243-261). London: Routledge.

Carter, S., Laurs, D., Chant, L., \& Wolfgramm-Foliaki, E. (2017). Indigenous knowledges and supervision: Changing the lens. Innovations in Education and Teaching International, 1-10, doi:10.1080/14703297.2017.1403941.

Chen, H. (2010). The transformation of knowledge production mode and the quality crises in doctoral education (in Chinese). Journal of Higher Education, 31(1), 57-63.

Chen, H., Shen, W., Gao, Y., \& Zhao, S. (2016). Degree authorisation audit mechanism reform and the path adjustment of postgraduate education governance in China (in Chinese). Educational Reseach, 1, 17-25. 
Chen, H., Zhao, S., Shen, W., \& Cai, L. (2011). Quality of Chinese doctoral education: achievement, challenges, and sollutions (in Chinese). Academic Degree and Graduation Education, 6, 40-45.

Clark, B. R. (1983). The Higher Education System: Academic Organization in Cross-national Perspective (Vol. Book, Whole). Berkeley, Los Angel, London: University of California Press.

CQAGDE (2010). China's Doctoral Education Quality Report (in Chinese). Beijing, China: Peking University Press.

Crossley, M. (2009). Rethinking Context in Comparative Education. In R. Cowen, \& A. M. Kazamias (Eds.), International Handbook of Comparative Education (pp. 1173-1187). Dordrecht: Springer Netherlands.

Crossley, M. (2010). Context matters in educational research and international development: Learning from the small states experience. [journal article]. Prospects, 40(4), 421-429, doi:10.1007/s11125-010-9172-4.

Crossley, M., \& Jarvis, P. (2001). Introduction: Context Matters. Comparative Education, 37(4), 405-408.

Enders, J., \& Musselin, C. (2008). Back to the future? The academic professions in the 21st century. Higher Education to 2030, $1,125-150$.

Fan, W., Cai, X., Zhao, S., Cheng, L., \& Wang, Y. (2011). Quality evaluation of Chinese doctoral education development (in Chinese). Academic Degree and Graduation Education, 1, 1-7.

Friedland, R., \& Alford, R. R. (1991). Bringing society back in: symbols, practices, and institutional contradictions. In W. W. Powell, \& P. J. DiMaggio (Eds.), The New Institutionalism in Organizational analysis (pp. 232-263). Chicago and London: University of Chicago Press.

Gao, Y., \& Shen, W. (2016). Employment of Chinese doctoral graduates: A study of graduates in 2014 from 75 universities (in Chinese). Academic Degree and Graduation Education, 49-56.

Ghignoni, E. (2017). Family background and university dropouts during the crisis: the case of Italy. [journal article]. Higher Education, 73(1), 127-151, doi:10.1007/s10734-016-0004-1.

Gu, J., John, L. S., \& Luo, Y. (forthcoming). Reproducing 'academic successors' or cultivating 'versatile experts': Influences of doctoral trainning on career expectations of Chinese PhD students Higher Education.

Gu, J., Lin, Y., Vogel, D., \& Tian, W. (2011). What are the major impact factors on research performance of young doctorate holders in science in China: a USTC survey. Higher Education, 62(4), 483-502, doi:10.1007/s10734-010-9400-0.

Gu, J., \& Luo, Y. (2016). Academic or market: the logic and paths of doctoral training pattern reform (in Chinese). Journal of Higher Education, 37(01), 49-56.

Gu, M. (2004). Cultural foundations of Chinese education (in Chinese) (Vol. 1, Vol. Book, Whole). Taiyuan: Shanxi Education Press.

Guo, J. (2009). Expansion of doctoral education, quality distribution and quality assurance of doctorate in Chinese universities: A perspective of the institutionalism (in Chinese). Peking University Education Review, 7(2), 21-46, doi:10.3969/j.issn.1671-9468.2009.02.003.

Harvey, L., \& Green, D. (1993). Defining quality. Assessment and Evaluation in Higher Education, 18(1), 9-34.

Hawkins, J. N. (2013). East-West? Tradition and the Development of Hybrid Higher Education in Asia. In D. Neubauer, J. C. Shin, \& J. N. Hawkins (Eds.), The Dynamics of Higher Education Development in East Asia: Asian Cultural Heritage, Western Dominance, Economic Development, and Globalization (pp. 51-67). New York: Palgrave Macmillan US.

Hayhoe, R. (1996). China's Universities--1895-1995: A Century of Cultural Conflict. Garland Studies in Higher Education (Garland Reference Library of Social Science, Vol. 997): Garland Publishing, Inc.

Kim, D., \& Roh, J. (2016). International doctoral graduates from China and South Korea: a trend analysis of the association between the selectivity of undergraduate and that of US doctoral institutions. Higher Education, 1-21, doi:10.1007/s10734-016-9984-0.

Lepori, B. (2016). Universities as hybrids: Applications of institutional Logics theory to higher education. In Theory and Method in Higher Education Research (pp. 245-264): Emerald.

Liu, Z., \& Luo, Y. (2015). Predicaments and countermeasures in doctoral education in the background of knowledge transformation (in Chinese). Journal of Graduate Education, 3, 38-49. 
Ma, W. (2007). The trajectory of Chinese doctoral education and scientific research. Research and Occasional Paper Series: CEHE.12.07, 1-12.

Mars, M. M., Bresonis, K., \& Szelényi, K. (2014). Science and engineering doctoral student socialization, logics, and the national economic agenda: alignment or disconnect? Minerva, 52(3), 351-379, doi:10.1007/s11024-014-9256-z.

Meyer, J. W., \& Scott, W. R. (1983). Organizational environments: Ritual and rationality. Beverly Hills ; London: Sage.

MoE (2005). Ministry of education's regulation on cultivating innovation capacity in postgraduate education (in Chinese). http://www.moe.edu.cn/publicfiles/business/htmlfiles/moe/s7065/201411/178119.html. Accessed Web Page 2016.

MoE (2014). National regulations on doctoral student recruitment (since 2014) (in Chinese). http://www.moe.gov.cn/publicfiles/business/htmlfiles/moe/s3114/201404/167125.html. Accessed Web Page 2016.

MoE (2016). Official announcement on cancelled doctoral programmes in 2014 (in Chinese). http://www.moe.edu.cn/srcsite/A22/moe_818/moe_820/201603/t20160325_235327.html. Accessed 19/12 2017.

MoE (2017). Statistics of China's educational development 2016 (in Chinese). Accessed 05/10 2017.

Peng, A. (2009). Changes and reforms on doctoral candidates' financial aid system in China (in Chinese). Academic Degrees and Graduate Education, 5, 18-22, doi:10.3969/j.issn.1001-960X.2009.05.005.

Pinheiro, R. (2011). In the Region, for the Region? A comparative study of the institutionalisation of the regional mission of universities.

Rhoads, R. A., Zheng, M., \& Sun, X. (2016). The methodological socialization of social science doctoral students in China and the USA. Higher Education, 1-17, doi:10.1007/s10734-016-0023-y.

Robinson, R. (2004). Pathways to completion: Patterns of progression through a university degree. [journal article]. Higher Education, 47(1), 1-20, doi:10.1023/B:HIGH.0000009803.70418.9c.

Shen, W. (2009). The evaluation of Ph. D training quality: concepts, methods and standpoints (in Chinese). Peking University Education Review, 7(2), 47-59, doi:10.3969/j.issn.1671-9468.2009.02.004.

Shen, W., \& Fan, A. (2013). What is a good doctoral supervision? (in Chinese). Academic Degree and Graduation Education, $3,45-51$.

Shen, W., Gao, Y., \& Zhao, S. (2017). Mono supervision or group supervision? A study of doctoral students' preference and satisfaction feedback (in Chinese). Academic Degree and Graduation Education, 7, 54-59.

Siu, K. W. M. (2011). Regional supervision collaboration in postgraduate design studies Global Journal of Engineering Education, 13(1), 20-25.

Thornton, P. H., \& Ocasio, W. (1999). Institutional Logics and the Historical Contingency of Power in Organizations: Executive Succession in the Higher Education Publishing Industry, 1958-1990. American Journal of Sociology, 105(3), 801-843, doi:10.1086/210361.

Thornton, P. H., Ocasio, W., \& Lounsbury, M. (2012). The Institutional Logics Perspective: A New Approach to Culture, Structure and Process (Vol. Book, Whole). New York: Oxford University Press.

Tierney, W. G., \& Rhoads, R. A. (1993). Enhancing promotion, tenure and beyond: Faculty socialization as a cultural process. Washington, D.C.: The George Washington University.

Wang, J. (2008). The development and changes of Chinese graduate school education under globalisation (in Chinese). China Mainland Studies, 51(1), 67-95.

Wang, M., Zhu, Y., Wang, J., \& Ma, L. (2016). On the construction of doctoral student source quality assurance mechanism practice at Zhejiang University (in Chinese). Journal of Graduate Education, 35(5), 28-32.

Wang, X. (2010). Higher Education as a Field of Study in China : Defining Knowledge and Curriculum Structure. Lanham, MD, United States: Lexington Books.

Wildy, H., Peden, S., \& Chan, K. (2015). The rise of professional doctorates: case studies of the Doctorate in Education in China, Iceland and Australia. Studies in Higher Education, 40(5), 761-774, doi:10.1080/03075079.2013.842968.

Wu, R. (2013). Reasons behind the challenges for doctoral students in China (in Chinese). Qing Nian Jiao Yu, 07, 107-112. 
Wu, R. (2017). Academic socialization of Chinese doctoral students in Germany: identification, interaction and motivation. European Journal of Higher Education, 7(3), 276-290, doi:10.1080/21568235.2017.1290880.

Välimaa, J. (2008). Cultural Studies in Higher Education Research. In J. Välimaa, \& O.-H. Ylijoki (Eds.), Cultural Perspectives on Higher Education (pp. 9-25): Springer Netherlands.

Yang, R. (2011). Self and the other in the Confucian cultural context: Implications of China's higher education development for comparative studies. International Review of Education, 57(3), 337-355.

Yang, R. (2012). Up and coming? Doctoral education in China. Australia Universities' Review, 54(1), 64-71.

Yang, R. (2017). The cultural mission of China's elite universities: examples from Peking and Tsinghua. Studies in Higher Education, 42(10), 1825-1838, doi:10.1080/03075079.2017.1376873.

Zhao, S., \& Shen, W. (2013). A comparative analysis of the doctoral education expansion between USA and China: based on data from 1960s (in Chinese). Educational Research, 11, 169-181.

Zheng, G., Cai, Y., \& Ma, S. (2017). Towards an analytical framework for understanding the development of a quality assurance system in an international joint programme. European Journal of Higher Education, 7(3), 243-260, doi:10.1080/21568235.2017.1290877.

Zheng, G., Kivistö, J., Shen, W., \& Cai, Y. (forthcoming). Comparing doctoral education in China and Finland: an institutional logics perspective In X. Du, H. Liu, A. A. Jensen, \& F. Dervin (Eds.), Nordic-Chinese Intersection on Education: Palgrave MacMillan.

Zhu, C., Cai, Y., Shen, W.-Q., \& François, K. (2017). Reforms and collaborations in Europe-China doctoral education. European Journal of Higher Education, 7(3), 219-226, doi:10.1080/21568235.2017.1290857.

Zhu, J. (2017). Understanding Chinese Engineering Doctoral Students in U.S. Institutions (1ed., East-West Crosscurrents in Higher Education). ebook: Springer Singapore. 